\title{
Up-conversion luminescence in low phonon heavy metal oxide glass co-doped with $\mathrm{Er}^{3+} / \mathrm{Ho}^{3+}$ ions
}

\author{
T. Ragin ${ }^{* 1}$, A. Baranowska ${ }^{1}$, M. Sołtys ${ }^{2}$, A. Górny ${ }^{2}$, J. Zmojda $^{3}$, M. Kochanowicz ${ }^{3}$, P. Miluski ${ }^{3}$, R. Jadach ${ }^{4}$, \\ D. Dorosz ${ }^{4}$ \\ ${ }^{1}$ Faculty of Mechanical Engineering, Bialystok University of Technology, Wiejska 45c, 15-351 Bialystok \\ ${ }^{2}$ Institute of Chemistry, University of Silesia, Szkolna 9, 40-007 Katowice \\ ${ }^{3}$ Faculty of Electrical Engineering, Bialystok University of Technology, Wiejska 45d, 15-351 Bialystok \\ ${ }^{4}$ AGH University of Science and Technology, Faculty of Materials Science and Ceramics, Mickiewicza 30, \\ 30-059 Krakow
}

Received March 10, 2018; accepted March 16, 2018; published March 31, 2018

\begin{abstract}
In this paper, heavy metal oxide glasses co-doped with erbium and holmium ions have been synthesized. Glass composition, based on bismuth and germanium oxides, has been selected in terms of high thermal stability $\left(\Delta \mathrm{T}=125^{\circ} \mathrm{C}\right)$, high refractive index $(\mathrm{n}=2.19)$ and low maximum phonon energy $\left(\mathrm{h} v_{\max }=724 \mathrm{~cm}^{-1}\right)$. Up-conversion luminescence spectra under the $980 \mathrm{~nm}$ laser diode excitation have been observed as a result of radiative transitions within the quantum energy level structures of $\mathrm{Er}^{3+}$ and $\mathrm{Ho}^{3+}$ ions. Optimization of rare earth ions content has been conducted, the highest emission intensity in the visible wavelength range has been observed in glass co-doped with molar concentration $0.5 \mathrm{Er}_{2} \mathrm{O}_{3} / 0.5 \mathrm{Ho}_{2} \mathrm{O}_{3}$.
\end{abstract}

Emission in a visible spectral range in glasses doped with rare earth ions has found a wide range of potential photonic applications, such as solid state UC lasers, bioimaging, display monitors and photodynamic therapy [1-3]. Known non-oxide glasses are characterized by good spectroscopic properties in the visible range and low phonon energy, but their low thermal stability, poor mechanical and chemical durability complicates their processing into photonic structures $[4,5]$. On the other hand, heavy metal oxide glasses possess advantageous properties for potential applications in the visible range, such as low phonon energy $\left(700 \mathrm{~cm}^{-1}\right)$, high thermal stability parameter $\left(\Delta \mathrm{T}>100^{\circ} \mathrm{C}\right)$ and high refractive index (2.26) [6, 7]. Incorporation of erbium and holmium ions into glass matrix enables obtaining up-conversion luminescence under IR radiation. $\mathrm{Er}^{3+}$ ions could be directly excited with $980 \mathrm{~nm}$ high power laser diode radiation, then an energy transfer phenomenon between rare earth ions could change the up-conversion emission intensity depending on their mutual concentration [8].

In the following work, bismuth-germanate glasses codoped with a different molar concentration of erbium and holmium oxides have been synthesized. The composition of host glass has been determined in terms of low phonon energy favorable for effective up-conversion processes. Emission intensity analysis in the visible range under high power laser diode excitation $\left(\lambda_{\text {exc }}=980 \mathrm{~nm}\right)$ determines the optimal concentration of rare earth ions.

A set of five glass samples based on bismuth, germanium, gallium and sodium oxides co-doped with erbium and holmium ions have been synthesized by using high purity compounds (Sigma-Aldrich, 99.99\%). Glass labels and lanthanides concentration have been presented in Table 1.

Table 1. Molar percentage of lanthanides incorporated into elaborated glass samples.

\begin{tabular}{ccc}
\hline \hline \multirow{2}{*}{ Sample } & $\mathbf{6 0}\left(\mathrm{Bi}_{2} \mathbf{O}-\mathrm{GeO}_{2}\right)-\mathbf{4 0}\left(\mathbf{N a}_{2} \mathbf{O}-\mathrm{Ga}_{2} \mathbf{O}_{3}\right)(\% \mathbf{m o l})$ \\
\cline { 2 - 3 } & $\mathbf{E r}_{2} \mathbf{O}_{\mathbf{3}}(\boldsymbol{\%} \mathbf{m o l})$ & $\mathbf{H o}_{2} \mathbf{O}_{\mathbf{3}}(\% \mathbf{m o l})$ \\
\hline EH1 & 0.25 & 0.25 \\
EH2 & 0.5 & 0.25 \\
EH3 & 0.5 & 0.5 \\
EH4 & 0.5 & 0.75 \\
EH5 & 0.5 & 1 \\
\hline \hline
\end{tabular}

The well-mixed powder was put into a platinum crucible and melted at $1050{ }^{\circ} \mathrm{C}$ for 15 . Next, the molten glass was poured onto a polished brass plate and annealed at $400{ }^{\circ} \mathrm{C}$ for 12 hours in order to reduce thermal stresses. Synthesized glasses have been subjected to mechanical processing to obtain a high optical quality, which is necessary during spectroscopic measurements. A series of samples with dimensions of $10 \times 10 \times 2 \mathrm{~mm}^{3}$ have been prepared to determine their optical properties. The FTIR spectra were recorded with a Bruker Company Vertex $70 \mathrm{v}$ spectrometer. The spectra were collected in the middle infrared regions (MIR) $1400 \div 400 \mathrm{~cm}^{-1}$ after 128 scans at $4 \mathrm{~cm}^{-1}$ resolution. The samples were prepared by the standard $\mathrm{KBr}$ pellets methods, the amount of the samples and $\mathrm{KBr}$ were precisely weighed. The absorption spectra in a spectral range of $460 \div 1000 \mathrm{~nm}$ were obtained using a Stellarnet Green-Wave Spectrometer as well as the luminescence spectra using a high power laser diode $\left(\lambda_{\text {exc }}=980 \mathrm{~nm}\right)$ as a pump source.

Figure 1 shows the absorbance spectra in the mid-infrared range obtained by FTIR spectroscopy. In the range from 400 to $1400 \mathrm{~cm}^{-1}$ three absorption bands have been characterized. The absorption band located at $724 \mathrm{~cm}^{-1}$ is associated with the bending vibrations of $\mathrm{Ge}-\mathrm{O}$ bonds in $\mathrm{GeO}_{4}$ molecules and determines the maximum phonon energy of synthesized glass $[9,10]$. Its value is 
significantly lower than in the known boron $\left(1400 \mathrm{~cm}^{-1}\right)$, phosphate $\left(1200 \mathrm{~cm}^{-1}\right)$ or silicate $\left(1100 \mathrm{~cm}^{-1}\right)$ glasses [11]. Taking into account up-conversion emission properties, the low phonon energy of the host glass enables effective IR to VIS conversion.

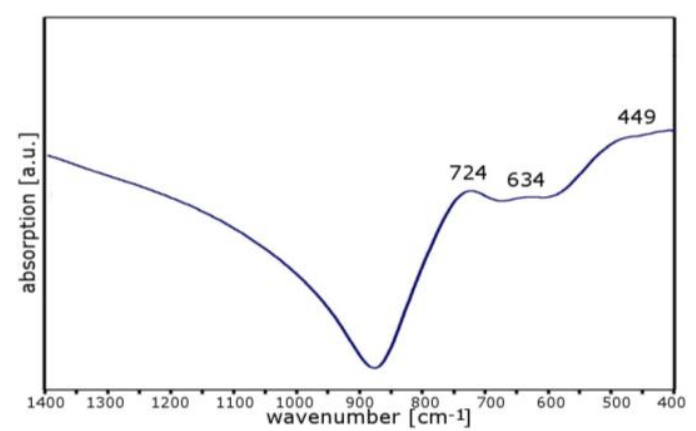

Fig. 1. FTIR results of synthesized bismuth-germanate glass.

Physical and thermal properties of the host glass have been shown in Table 2. The stability parameter of the glass is defined as a temperature gap between crystallization and transformation temperature. Obtained thermal stability parameter equals $125^{\circ} \mathrm{C}$, which is higher than in other bismuth-germanate glasses [3]. The high value of $\Delta \mathrm{T}$ parameter determines the low probability of crystallization effects during further processing of material info photonic structures [6].

Table 2. Properties of bismuth-germanate base glass [12].

\begin{tabular}{cc}
\hline \hline Parameter & Value \\
\hline Refractive index $n($ at $632.8 \mathrm{~nm})$ & 2.19 \\
Maximum phonon energy $h v\left[\mathrm{~cm}^{-1}\right]$ & 724 \\
Transformation temperature $T_{g}\left[{ }^{\circ} \mathrm{C}\right]$ & 416 \\
Crystallization temperature $T_{x}\left[{ }^{\circ} \mathrm{C}\right]$ & 541 \\
Stability parameter of glass $\Delta T\left[{ }^{\circ} \mathrm{C}\right]$ & 125 \\
\hline \hline
\end{tabular}

The absorption coefficient spectrum of bismuthgermanate glass co-doped with $0.5 \mathrm{~mol} \% \mathrm{Er}_{2} \mathrm{O}_{3}$ and $0.5 \mathrm{~mol}_{\%} \mathrm{Ho}_{2} \mathrm{O}_{3}$ has been presented in Fig. 2. The presence of a large molar amount of $\mathrm{Bi}_{2} \mathrm{O}_{3}$ in the glass matrix results in red-shifting of the UV absorption edge (at about 550nm). This phenomenon is typical of heavy metal ions due to weaker metal-oxygen bond strength [13]. In the range from 460 to $1000 \mathrm{~nm}$, six characteristic absorption bands have been identified at wavelengths of 488, 522, 540, 651, 801 and 980nm. They are associated with a complex structure of lanthanide ions and correspond to transitions from $\mathrm{Er}^{3+}$ ground state ${ }^{4} \mathrm{I}_{15 / 2}$ to higher energy levels ${ }^{4} \mathrm{~F}_{7 / 2},{ }^{2} \mathrm{H}_{11 / 2},{ }^{4} \mathrm{~S}_{3 / 2},{ }^{4} \mathrm{~F}_{9 / 2},{ }^{4} \mathrm{I}_{9 / 2}$ and ${ }^{4} \mathrm{I}_{11 / 2}$, respectively. At a wavelength of $651 \mathrm{~nm}$ we have observed the superposition of two absorption bands originating from the ground state absorption phenomenon in erbium and holmium ions $\left(\mathrm{Er}^{3+}:{ }^{4} \mathrm{I}_{15 / 2} \rightarrow{ }^{4} \mathrm{~F}_{9 / 2}\right.$ and $\left.\mathrm{Ho}^{3+}: \mathrm{I}_{8} \rightarrow{ }^{4} \mathrm{~F}_{4}\right)$. The absorption band at a wavelength of $980 \mathrm{~nm}$ has been used for an optical excitation process $\left(\right.$ GSA $\left.\mathrm{Er}^{3+}:{ }^{4} \mathrm{I}_{15 / 2} \rightarrow{ }^{4} \mathrm{I}_{11 / 2}\right)$ with high power laser diode radiation.

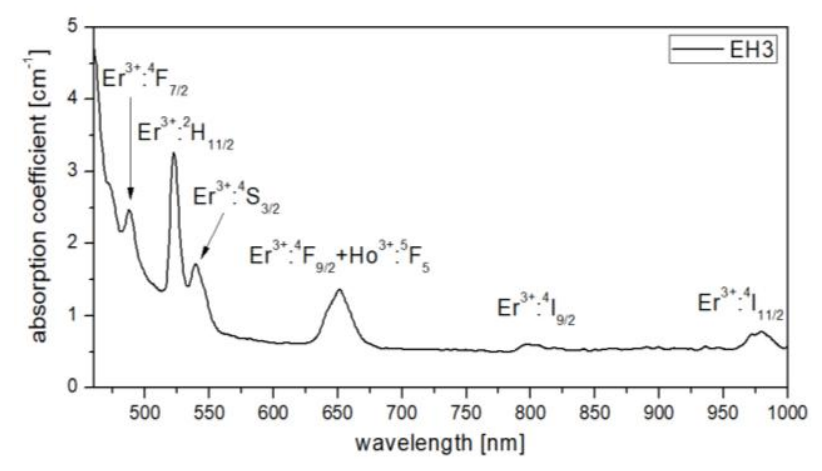

Fig. 2. The absorption coefficient spectra of bismuth-germanate glass doped with $\mathrm{Er}^{3+} / \mathrm{Ho}^{3+}$ ions.

Figure 3 shows the upconversion luminescence spectra in synthesized glasses co-doped with rare earth ions under $980 \mathrm{~nm}$ optical excitation. In a wavelength range of $500 \div$ $900 \mathrm{~nm}$ four emission bands, originating from radiative transitions within erbium and holmium ions, have been observed.



Fig. 3. The up-conversion emission spectra of bismuth-germanate glasses co-doped with $\mathrm{Er}^{3+} / \mathrm{Ho}^{3+}$ ions.

According to the previous research [14], absorption and luminescence spectra, a simplified energy level diagram with possible energy transfer mechanisms between erbium and holmium ions has been presented in Figure 4. Erbium ions are excited with $980 \mathrm{~nm}$ high power laser diode radiation to ${ }^{4} \mathrm{I}_{11 / 2}$ level due to the ground state absorption (GSA). The ${ }^{4} \mathrm{I}_{11 / 2}$ energy level can be depopulated by excited state absorption (ESA1), which leads to the population of ${ }^{4} \mathrm{~F}_{7 / 2}$ level or non-radiative relaxation to ${ }^{4} \mathrm{I}_{13 / 2}$ multiplet and then ESA2 to ${ }^{4} \mathrm{~F}_{9 / 2}$ level. Due to non-radiative relaxation processes, erbium ions could transfer radially from ${ }^{4} \mathrm{~S}_{3 / 2},{ }^{4} \mathrm{~F}_{9 / 2}$ and ${ }^{4} \mathrm{I}_{9 / 2}$ excited level to the ${ }^{4} \mathrm{I}_{15 / 2}$ ground level emitting 552, 672 and $852 \mathrm{~nm}$ radiation, respectively. Holmium ions could be excited to ${ }^{5} \mathrm{I}_{7}$ and ${ }^{5} \mathrm{I}_{6}$ levels due to the energy transfer ET1 and ET2 from $\mathrm{Er}^{3+}$ ions. Excited state absorption ESA3 and ESA4 populate ${ }^{5} \mathrm{~F}_{5}$ and ${ }^{5} \mathrm{~F}_{4}$ higher quantum levels, 
then energy can be transferred to erbium ${ }^{2} \mathrm{H}_{11 / 2}$ and ${ }^{4} \mathrm{~F}_{9 / 2}$ levels with ET4 and ET3 processes or transferred radially to the ${ }^{5} \mathrm{I}_{8}$ ground level or ${ }^{5} \mathrm{I}_{7}$ level emitting 557, 660 or $755 \mathrm{~nm}$ radiation, respectively.

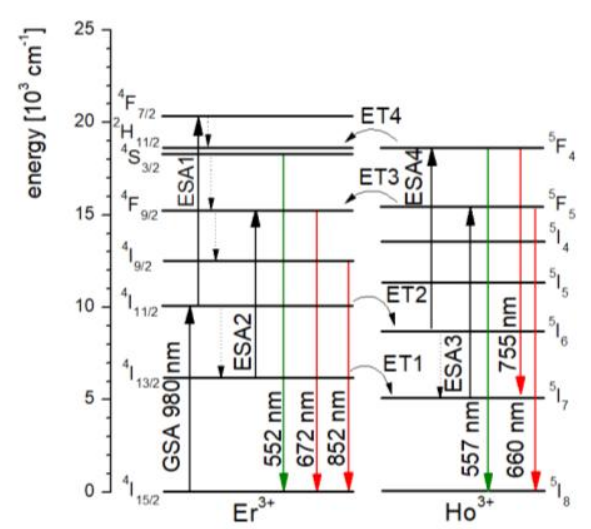

Fig. 4. Simplified energy level diagram of $\mathrm{Er}^{3+} / \mathrm{Ho}^{3+}$ ions with possible energy transfer mechanisms.

The highest emission intensity in all luminescence bands has been observed in the sample EY3 co-doped with the molar concentration $0.5 \mathrm{Er}_{2} \mathrm{O}_{3} / 0.5 \mathrm{Ho}_{2} \mathrm{O}_{3}$. The higher concentration of holmium oxide results in the luminescence quenching phenomenon due to energy migration between rare earth ions.

In this work, a set of bismuth-germanate glasses doped with erbium and holmium ions have been synthesized. Glass matrix is characterized with high thermal stability $\left(\Delta \mathrm{T}=125^{\circ} \mathrm{C}\right)$, high refractive index $(\mathrm{n}=2.19)$ and low maximum phonon energy $\left(\mathrm{h} v_{\max }=724 \mathrm{~cm}^{-1}\right)$. As a result of the up-conversion luminescence measurements $\left(\lambda_{\text {exc }}=\right.$ $=980 \mathrm{~nm}$ ), four emission bands in the visible range have been observed. The optimization of lanthanides molar content has been conducted in terms of maximum upconversion emission, which has been observed in glass co-doped with $0.5 \mathrm{~mol} \% \mathrm{Er}_{2} \mathrm{O}_{3} / 0.5 \mathrm{~mol} \% \mathrm{Ho}_{2} \mathrm{O}_{3}$. Considering the obtained results, the fabricated glass codoped with rare earth ions is a promising material for potential applications operating in the visible range.

The research activity was supported by the National Science Centre (Poland) granted on the basis of the decision No. DEC-2016/23/N/ST8/03523.

\section{References}

[1] F. Zhang, Z. Bi, A. Huang, Z. Xiao, Opt. Materials 41, 112 (2014).

[2] S. Li, S. Ye, T. Liu, H. Wang, D. Wang, J. All. Comp. 658, 85 (2016).

[3] J. Fu, X. Zhang, Z. Chao, Z. Li, J. Liao, D. Hou, H. Wen, X. Lu, X. Xie, Opt. Laser Tech. 88, 280 (2017).

[4] Y. Tian, R. Xu, L. Hu, J. Zhang, J. Quant. Spec. Rad. Tra. 113, 87 (2012).

[5] M. Zhang, A. Yang, Y. Peng, B. Zhang, H. Ren, W. Guo, Y. Yang, C. Zhai, Y. Wang, Z. Yang, D. Tang, Mat. Res. Bul. 70, 55 (2015).

[6] G. Yang, T. Li, J. Rare Earths 26, 924 (2008).

[7] Y. Guo, Y. Tian, L. Zhang, L. Hu, J. Zhang, J. Non-Cryst. Solids 377, 119 (2013).

[8] Z. Hou, Z. Xue, F. Li, M. Wang, X. Hu, S. Wang, J. All. Comp. 577, 523 (2013).

[9] X. Li, Q. Nie, S. Dai, T. Xu, L. Lu, X. Zhang, J. All. Comp. 454, 510 (2008)

[10] S.S. Rojas, J.E. De Souza, M.R.B. Andreeta, A.C. Hernandes, J. Non-Cryst. Solids 356, 2942 (2010).

[11]M.S. Ebrahim, Mid-infrared coherent sources and applications (Springer, 2008).

[12]T. Ragin, J. Zmojda, M. Kochanowicz, P. Miluski, P. Jelen, M. Sitarz, D. Dorosz, J. Non-Cryst. Solids 457, 169 (2017).

[13] K. Biswas, A.D. Sontakke, R. Sen, K. Annapurna, Spectr. Acta. Part A, Mol. Biomol. Spectr. 112, 301 (2013).

[14]R.S. Romaniuk, D. Dorosz, J. Żmojda, M. Kochanowicz, W. Mazerski, Proc. of SPIE 8903, 890307 (2013). 